\section{Neuroprotective activity of Ethanolic Extract of Tinospora cordifolia on LPS induced Neuroinflammation}

\section{Abstract}

Background: Neuroinflammation has been implicated in the pathogenesis or the progression of the variety of acute and chronic neurological and neurodegenerative disorders including Alzheimer's disease.

Aim: The present study is to investigate the ethanolic extract of Tinospora cordifolia on LPS induced behavioral alterations, oxidative stress and neuronal damage in rats.

Methods: Adult male Wistar rats were divided into five groups six in each. Group I treated with normal saline $(0.9 \% \mathrm{NaCl}$ i.p.), group ii treated with normal saline + LPS $(100 \mu \mathrm{g} / \mathrm{kg}$ i.p.), group iii treated with Aspirin $(200 \mathrm{mg} / \mathrm{kg})+\mathrm{LPS}(100 \mu \mathrm{g} / \mathrm{kg})$, Group IV treated with EETC $(200 \mathrm{mg} / \mathrm{kg})+$ LPS $(100 \mu \mathrm{g} / \mathrm{kg})$ and Group V treated with EETC $(400 \mathrm{mg} / \mathrm{kg})+$ LPS $(100 \mu \mathrm{g} / \mathrm{kg})$ for 14 days followed by single challenged of LPS to all the groups except control rats. On $15^{\text {th }}$ day onwards, various behavioral assessment such as body weight, rectal temperature, locomotor activity, cognitive and memory assessment were carried out. Rats were sacrificed, and brain was isolated and estimated antioxidant levels (GSH, SOD, TBARS and CAT) and neuronal damage in the region of hippocampus were analyzed.

Results: LPS treated rats significantly $(P<0.001)$ decreased the body weight, locomotor activity, latency period in passive avoidance test and anti-oxidant levels in GSH, SOD and CAT and increased the rectal temperature and lipid peroxidase level (TBARS) compare to control rats. Pretreated with Aspirin $200 \mathrm{mg} / \mathrm{kg}$ rats and EETC ( 200 and $400 \mathrm{mg} / \mathrm{kg}$ ) rats significantly attenuated the LPS induced behavioral alteration, oxidative damage and neuronal damage.

Conclusion: The ethanolic extract of Tinospora cordifolia showed neuroprotective activity due to the presence of phytochemical constituents such as alkaloids, glycosides, diterpenoid lactones, berberine, flavonoids, saponins.

Keywords: Neuroinflammation; Tinospora cordifolia; Hippocampus; Lipopolysaccharide

\section{Prakash R*, Sandhya E, Ramya N, Dhivya R, Priyadarshini $M$ and Sakthi Priya B}

Department of Pharmacology, KK College of Pharmacy, Gerugambakkam, Chennai, India

\section{*Corresponding author: Dr. Prakash R \\ ” prakasheeba@rediffmail.com \\ Department of Pharmacology, KK College of Pharmacy, Gerugambakkam, Chennai-600128, India.}

Tel: 9940634459

Citation: Prakash R, Sandhya E, Ramya N, Dhivya R, Priyadarshini M, et al. (2017) Neuroprotective activity of Ethanolic Extract of Tinospora cordifolia on LPS induced Neuroinflammation. Transl Biomed. Vol.8 No.4:135

Received: September 29, 2017; Accepted: October 27, 2017; Published: November 03, 2017

\section{Abbreviations}

LPS: Lipopolysaccharide; EETC: Ethanolic Extract of Tinospora cordifolia; TLR: Toll-Like Receptor; NSAID: Non-Steroidal Anti-Inflammatory Drug; GSH: Glutathione Reductase; SOD: Superoxide Dismutase; TBARS: Thiobarbituric Acid Reactive Substances; CAT: Catalase; ROS: Reactive Oxygen Species

\section{Introduction}

Lipopolysaccharide (LPS), also known as bacterial endotoxin are biologically active substances, a major cell constituent present on the outer membrane of the cell wall of most Gramnegative bacteria [1,2]. Bacterial lipopolysaccharide consists of a polysaccharide region that is anchored on the outer bacterial 
membrane by a specific carbohydrate lipid moiety termed as Lipid A. This lipid A is responsible for the potent immunostimulatory property of LPS $[3,4]$. LPS projects its potency and act as an endotoxin by its greater affinity towards Toll-like receptor 4 (TLR 4) [5]. TLRs initiate key inflammatory responses and also shape adaptive immunity. LPS binds to TLR 4 which interacts with three different extracellular proteins namely LPS- binding protein (LPB), CD14 (Pattern recognition receptor-cluster of differentiation 14), Myeloid differentiation protein 2 (MD-2), to induce a signaling cascade, leading to activation of NF-KB-dependent induction of pro-inflammatory cytokines such as TNF- $\alpha, \mathrm{IL}-1 \beta, \mathrm{IL}-6, \mathrm{COX}$, Prostaglandins and free radicals $[3,6-8]$. Thus, it is showed that by promoting the formation of free radicals, cytokines and other pro-inflammatory mediators in brain, blood as well as in tissue. LPS acts as a strong stimulator of potent immune system and produces a potent immunostimulant effect. As an outcome of potent stimulation of immune system by LPS, there results neuroinflammation.

Currently the term "Neuroinflammation" is used to describe the inflammatory response originated in the CNS due to the accumulation of glial cells by activating the immune component. But currently there are drugs available for the treatment of neuroinflammation which includes classes of drugs like NSAIDS, Opioid antagonists, selective COX inhibitor, NMDA receptor antagonists and rarely antibiotics $[9,10]$. But these allopathic medicines on usage, although effective at relieving pain and inflammation, produce undesirable serious side effects. For example, NSAIDS causes gastric irritation, abdominal or stomach pain, nausea, cramping, ringing in ears, confusion etc [11]. On the other hand, Opioid antagonists also results in unwanted effects like loss of appetite, dizziness, nervousness, etc. [12]. As an alternative method of treatment, in order to avoid all major side effects, we have focused our research work on Traditional drugs. These herbal medicines can be used to treat patients with lesser or no side effects as with allopathy.

Tinospora cordifolia (wild) is used in ayurvedic "Rasayanas", is a large, glabrous, deciduous, climbing shrub belonging to the family Menispermaceae indigenous to the tropical areas of India, Myanmar and Srilanka $[13,14]$. It is widely used in veterinary folk medicine, ayurvedic system of medicine for its general tonic, anti-diabetic, antipyretic, antispasmodic, anti-arthritic, antioxidant, anti-allergic, anti-stress, anti-inflammatory etc [1518]. In the present study, we have investigated the effect of Ethanolic Extract of Tinospora cordifolia (EETC) which attenuates LPS induced neuroinflammation by down-regulating the levels of pro-inflammatory cytokines such as TNF- $\alpha$, IL-1 $1 \beta$, IL-6, COX, NOS etc.

Till date, no research work is scientifically validated on Tinospora cordifolia on LPS induced neuroinflammation in rats. The present investigation was therefore aimed at evaluating the neuroprotective effect of Tinospora cordifolia against LPS induced sickness behavior in rats.

\section{Materials and Methods}

\section{Authentication of plant material}

The flower part of the plant Tinospora cordifolia (Menispermaceae) was collected from Andhra Pradesh. The plant material was identified and authenticated by Dr. D. Narasimhan, Associate Professor, and Centre for Floristic Research, Madras Christian College, Tambaram, Chennai.

Preparation of extract: The fresh flower was collected and washed, chopped, dried at room temperature, and was made into coarse powder. The powder was extracted with $98 \%$ ethanol $\left(68^{\circ} \mathrm{C}-78^{\circ} \mathrm{C}\right)$ in Soxhlet apparatus for $24 \mathrm{~h}$. The extracts were concentrated on water bath $\left(50^{\circ} \mathrm{C}\right)$. The yield of the ethanolic extract was found to be $1.0 \%(\mathrm{w} / \mathrm{w})$ which was then stored at room temperature.

\section{Animals}

Adult male Wistar rat (160-180 g: 30 rats) were procured from $\mathrm{CL}$ Baid Metha College of Pharmacy, Chennai and divided into five groups of six animals each. The rats were housed in colony cages at an aberrant temperature of $25^{\circ} \mathrm{C} \pm 2^{\circ} \mathrm{C}$ with a $12 \mathrm{~h}$ light/ dark cycle. The animals had free access to standard pellet diet and drinking water. Behavioral studies were carried out in a quiet room between 9.00 am and 11.00 am to avoid circadian variation. The study was approved by Institutional Animal Ethical Committee, and work was carried out as per CPCSEA Guidelines, New Delhi.

\section{Drugs and chemicals}

Lipopolysaccharide (Sigma Aldrich, Mumbai), Aspirin (Madras Pharmaceuticals Ltd., Chennai), Thiobarbituric acid (S.d. Fine Chemicals Ltd., Mumbai), and SOD (HiMedia Research Laboratory, Mumbai) were obtained. All other chemicals and reagents unless specified were of analytical grade.

\section{Experimental Design}

The animals are divided into five groups with six rats each. The first group (control) received normal saline $(0.9 \% \mathrm{NaCl}$, p.o.) once daily for 14 days. The second group treated saline for 14 days followed by LPS challenge $(100 \mu \mathrm{g} / \mathrm{kg}$, i.p.). The third group received Aspirin ( $200 \mathrm{mg} / \mathrm{kg}$ p.o) for 14 days followed by LPS (100 $\mu \mathrm{g} / \mathrm{kg}$ i.p.). The fourth group received EETC (200 mg/kg p.o) for 14 days followed by LPS (100 $\mathrm{mg} / \mathrm{kg}$ i.p.). The fifth group received EETC (400 mg/kg p.o) for 14 days followed by LPS $(100 \mu \mathrm{g} / \mathrm{kg}$ i.p.). All drugs were prepared freshly and given once daily in the morning and followed the same regimen (Table 1).

Table 1 Treatment according to group.

\begin{tabular}{cc} 
Groups & Treatment \\
\hline Group-I & Normal saline $(0.9 \% \mathrm{NaCl}$ i.p. $)$ \\
\hline Group-II & Normal saline + LPS $(100 \mu \mathrm{g} / \mathrm{kg}$ i.p. $)$ \\
\hline Group-III & Aspirin $(200 \mathrm{mg} / \mathrm{kg}$ p.o) + LPS $(100 \mu \mathrm{gg} / \mathrm{kg}$ i.p. $)$ \\
\hline Group-IV & EETC $(200 \mathrm{mg} / \mathrm{kg}$ p.o $)+$ LPS $(100 \mu \mathrm{gg} / \mathrm{kg}$ i.p. $)$ \\
\hline Group-V & EETC $(400 \mathrm{mg} / \mathrm{kg}$ p.o $)+$ LPS $(100 \mu \mathrm{g} / \mathrm{kg}$ i.p. $)$ \\
\hline
\end{tabular}




\section{Estimation of body weight}

The body weights were measured before and after treatment with extracts and drug control. Body weight of all experimental animals was measured using a digital weighing scale.

\section{Measurement of rectal temperature}

Rectal temperature was measured with a thermostat probe inserted about $1.3 \mathrm{~cm}$ into the rectum and taped to the base of the tail. Temperature was monitored continuously.

\section{Behavioral assessment}

Locomotor activity: The spontaneous locomotor activity was monitored using digital Actophotometer equipped with infrared sensitive photo cells. The apparatus was placed in a darkened, light and sound attenuated, and ventilated testing room. Each interruption of beam on the $x$ or $y$ axis generated an electric impulse, which was presented on a digital counter. The activity was performed on day $14^{\text {th }}$ on animals following LPS administration and the respective values were expressed as counts per $5 \mathrm{~min}$ [19].

\section{Step through passive avoidance test}

The step through passive avoidance apparatus consisted of an illuminated chamber $(11.5 \mathrm{~cm} \hat{A} 9.5 \mathrm{~cm} \hat{A} 11 \mathrm{~cm})$ attached to a darkened chamber $(23.5 \mathrm{~cm} \hat{A} 9.5 \mathrm{~cm} \hat{A} 11 \mathrm{~cm})$ containing a metal floor that could deliver foot shocks. The two compartments were separated by a guillotine door. The illuminated chamber was lit with a $25 \mathrm{~W}$ lamp. Briefly, rat was placed in the dimly lit room containing the apparatus $0.5 \mathrm{~h}$ before training to acclimatize to the new environment. Each rat was then placed individually into the illuminated chamber, facing away from the door to the dark chamber, and allowed to acclimatize for $1 \mathrm{~min}$. As soon as the rat entered the dark chamber, the door was slid back into place, triggering a mild foot shock $(0.3 \mathrm{Ma}, 50 \mathrm{~Hz}, 5 \mathrm{~s})$. The rat was then immediately removed from the chamber and returned to its home cage. The latency (time used to change compartment) was recorded. The retention test was conducted $24 \mathrm{~h}$ later (day 15) with the rat again being placed in the illuminated chamber and subjected to the same protocol in the absence of foot shock. The upper time limit was set at 300 secs [20].

\section{Dissection and homogenization}

After the treatment period, animals were sacrificed on $16^{\text {th }}$ day by decapitation under mild anaesthesia. The brains were immediately removed, forebrain was dissected out, and cerebellum was discarded. Brains were put on ice and rinsed in ice-cold isotonic saline to remove blood. A $10 \%(w / v)$ tissue homogenate was prepared in $0.1 \mathrm{M}$ phosphate buffer $(\mathrm{pH} 7.4)$. The homogenate was centrifuged at $10,000 \mathrm{~g}$ for 15 minutes and aliquots of supernatant obtained were used for biochemical estimation.

\section{Estimation of glutathione reductase (GSH)}

The reaction mixture containing $1 \mathrm{~mL}$ of phosphate buffer, $0.5 \mathrm{~mL}$ of ethylenediamine tetraacetic acid (EDTA), $0.5 \mathrm{~mL}$ of oxidized glutathione and $0.2 \mathrm{~mL}$ of NADPH was made up to $3 \mathrm{~mL}$ with distilled water. After the addition of $0.1 \mathrm{~mL}$ of tissue homogenate, the change in optical density at $340 \mathrm{~nm}$ was monitored for $2 \mathrm{~min}$ at $30 \mathrm{~s}$ intervals. One unit of the enzyme activity was expressed as moles of NADPH oxidized/min/mg protein [21].

\section{Estimation of superoxide dismutase (SOD)}

The supernatant $(500 \mu \mathrm{L})$ was added to $0.8 \mathrm{ml}$ of carbonate buffer (100 mM, pH 10.2) and $100 \mu \mathrm{L}$ of epinephrine ( $3 \mathrm{mM})$. The change in absorbance of each sample was then recorded at 480 $\mathrm{nm}$ in spectrophotometer for $2 \mathrm{~min}$ at an interval of $15 \mathrm{~s}$. Parallel blank and standard were run for determination of SOD activity. One unit of SOD is defined as the amount of enzyme required to produce $50 \%$ inhibition of epinephrine auto-oxidation. The reaction mixtures are diluted $1 / 10$ just before taking the readings in the spectrophotometer [22].

\section{Assay of thiobarbituric acid reactive substances (TBARS)-malonaldehyde level}

The amount of malonaldehyde was used as an indirect measure of lipid peroxidation and was determined by reaction with thiobarbituric acid (TBA) [23]. Briefly, $1 \mathrm{~mL}$ of aliquots of supernatant was placed in test tubes and added to $3 \mathrm{ml}$ of TBA reagent: TBA $0.38 \%(w / w), 0.25 \mathrm{M}$ hydrochloric acid $(\mathrm{HCl})$, and trichloroacetic acid (TCA 15\%). The solution was shaken and placed for $15 \mathrm{~min}$, followed by cooling in an ice bath. After cooling, solution was centrifuged to $3500 \mathrm{~g}$ for $10 \mathrm{~min}$. The upper layer was collected and assessed with a spectrophotometer at $532 \mathrm{~nm}$. Results were expressed as nanomoles per $\mathrm{mg}$ of protein. The concentration of MDA was calculated per mg of protein.

\section{Estimation of catalase (CAT) level}

The catalase activity was assessed by the method of Aebi [24]. The assay mixture consists of $0.05 \mathrm{~mL}$ of supernatant of tissue homogenate $(10 \%)$ and $1.95 \mathrm{~mL}$ of $50 \mathrm{mM}$ phosphate buffer $(\mathrm{pH}$ 7.0) in $3 \mathrm{~mL}$ cuvette. $1 \mathrm{~mL}$ of $30 \mathrm{mM}$ hydrogen peroxide $\left(\mathrm{H}_{2} \mathrm{O}_{2}\right)$ was added and changes in absorbance were followed for $30 \mathrm{~s}$ at $240 \mathrm{~nm}$ at $15 \mathrm{~s}$ intervals. The catalase activity was calculated using the millimolar extinction coefficient of $\mathrm{H}_{2} \mathrm{O}_{2}(90.071 \mathrm{~mm}$ mol cm$~^{-1}$ ) and the activity was expressed as micromoles of $\mathrm{H}_{2} \mathrm{O}_{2}$ oxidized per minute per milligram protein.

\section{Histopathological assessments}

The brains from control and experimental groups were removed without any injury after opening the skull. The collected sample was washed with normal saline and fixed in $10 \%$ neutral formalin for $48 \mathrm{~h}$ for further histological observations. Hippocampus section was taken at $5 \mu \mathrm{m}$ thickness processed in alcohol xylene series and was stained with crystal violet. The brain sections were examined microscopically for histopathological changes [25].

\section{Statistical analysis}

The results were expressed as mean \pm SEM. Statistical differences between the mean of various groups were analysed by using variance followed by the Turkey multiple comparison test. Differences were considered significantly at $\mathrm{P}<0.05$. 


\section{Results}

\section{Effect of EETC on LPS induced alterations in body weight}

LPS $(100 \mu \mathrm{g} / \mathrm{kg})$ treated rats significantly $(P<0.001)$ decreased in body weight when compared to control group. Aspirin (200 $\mathrm{mg} / \mathrm{kg}$ ) treated group showed significantly $(P<0.001)$ increased in body weight compare to LPS treated rats. EETC (200 and 400 $\mathrm{mg} / \mathrm{kg}$ ) administered group significantly $(P<0.001)$ increased the body weight when compared with LPS treated group (Figure 1).

\section{Effect of EETC on LPS induced alterations in rectal temperature}

LPS treated rats showed significantly $(P<0.001)$ increased the rectal temperature when compared with control rats. Aspirin $(200 \mathrm{mg} / \mathrm{kg}$ ) treated group reversed the rectal temperature significantly $(P<0.001)$ when compared with LPS treated group. In EETC (200 and $400 \mathrm{mg} / \mathrm{kg}$ ) treated group reduced the rectal temperature significantly $(P<0.001)$ when compared with LPS treated group (Figure 2).

\section{Effect of EETC on LPS induced alterations in locomotor activity}

LPS $(100 \mu \mathrm{g} / \mathrm{kg})$ treated rats significantly $(p<0.001)$ decreased the locomotor activity in the actophotometer when compared to control rats. Pretreatment with Aspirin $200 \mathrm{mg} / \mathrm{kg}$ along with LPS significantly $(p<0.001)$ increased the locomotor activity in the actophotometer when compared to LPS treated rats. Pretreatment with EETC $(200 \mathrm{mg} / \mathrm{kg})$ and EETC $(400 \mathrm{mg} / \mathrm{kg})$ significantly $(p<0.001)$ increased the locomotor activity in the actophotometer when compared to LPS treated rats (Figure 3).

\section{Effect of EETC on LPS induced memory impairment in passive avoidance test}

The effect of EETC on long-term memory was investigated in the step-through passive avoidance test. During the training session (Day 1), there was no significant difference between

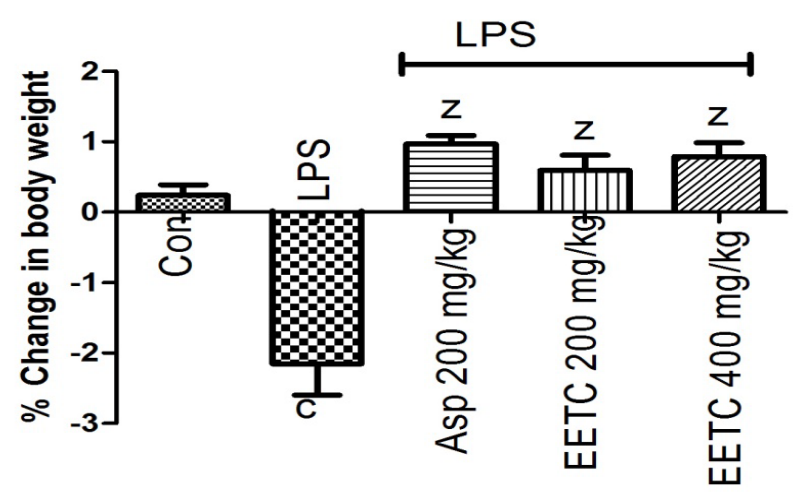

Figure 1 Effect of EETC on LPS induced alterations in Body weight. Values are expressed mean $\pm S E M$. ${ }^{C P}<0.001$ compared to control rats. ${ }^{2} \mathrm{P}<0.001$ compared to LPS treated rats.

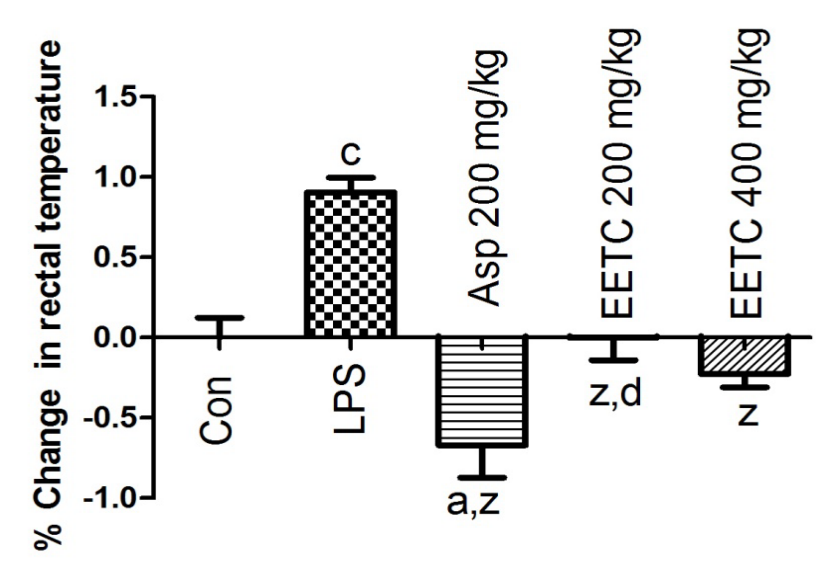

Figure 2 Effect of EETC on LPS induced alterations in Rectal temperature. Values are expressed mean \pm SEM. ${ }^{c} \mathrm{P}<0.001$ and ${ }^{\mathrm{a}} \mathrm{P}<0.05$ compared to control rats. ${ }^{2} \mathrm{P}<0.001$ compared to LPS treated rats. ${ }^{\mathrm{d}} \mathrm{P}<0.001$ compared to aspirin treated rats.

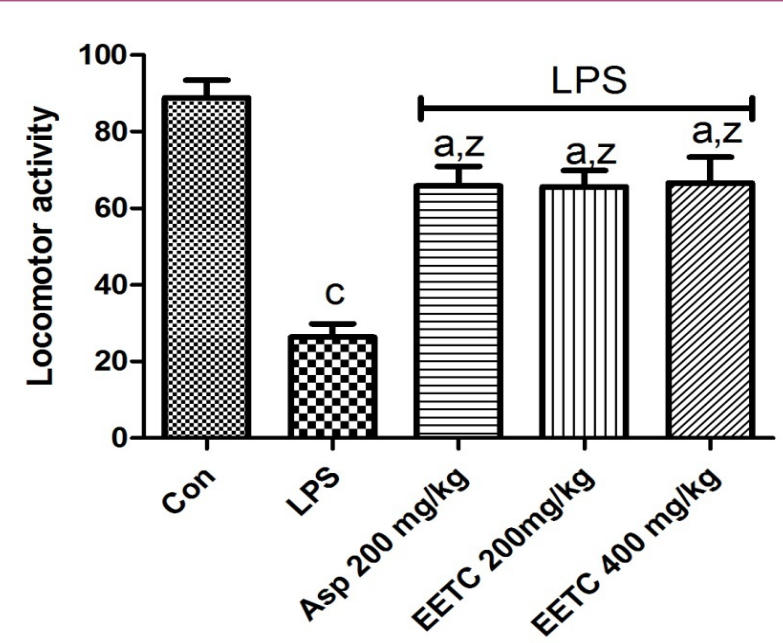

Figure 3 Effect of EETC on LPS induced alterations in Locomotion using actophotometer. Values are expressed mean \pm SEM. ${ }^{\mathrm{C}} \mathrm{P}<0.001$ and a $\mathrm{P}<0.05$ compared to control rats. ${ }^{2} \mathrm{P}<0.001$ compared to LPS treated rats.

any groups. However, there was a significant difference in the retention latency between the groups. LPS treated rats showed a significantly $(P<0.001)$ lower latency when compare to control group which was performed $24 \mathrm{hrs}$ after the training period. The reduced retention latency indicates learning and memory impairment in rats. This effect was reversed significantly $(P<0.001)$ by administration of EETC 200 and $400 \mathrm{mg} / \mathrm{kg}$. Aspirin treated group significantly increased the latency period during retention test when compared to LPS treated group. There was no significant difference in the retention latency period between the doses of EETC $200 \mathrm{mg} / \mathrm{kg}$ and EETC $400 \mathrm{mg} / \mathrm{kg}$ (Table 2).

\section{Effect of EETC on anti-oxidant level}

Effect of EETC on LPS induced alterations in GSH level: LPS treated rats significantly $(P<0.001)$ decreased the level of GSH 
when compared to control rats. Aspirin treated rats significantly $(P<0.001)$ increased the GSH level when compared with the LPS treated rats. EETC (200 and $400 \mathrm{mg} / \mathrm{kg}$ ) treated rats increased the level of GSH produce significantly $(P<0.001)$ when compared with LPS treated rats. There was no significant difference in the level of GSH between EETC $200 \mathrm{mg} / \mathrm{kg}$ and $400 \mathrm{mg} / \mathrm{kg}$ (Table 3).

Effect of EETC on LPS induced alterations in SOD level: LPS treated rats produced significantly $(P<0.001)$ decrease in the level of SOD compared with control group. Aspirin treated group showed significantly $(P<0.001)$ increased the level of SOD when compared with LPS treated group. EETC (200 and $400 \mathrm{mg} / \mathrm{kg}$ ) restored significantly $(P<0.001)$ the level of SOD but the better antioxidant effect was obtained from EETC of $400 \mathrm{mg} / \mathrm{kg}$ than the EETC (200 mg/kg) (Table 3).

Effect of EETC on LPS induced alterations in TBARS level: LPS treated group significantly $(P<0.001)$ increased the level of TBARS when compared with the control group. Aspirin treated group decreased the TBARS level significantly $(P<0.001)$ when compared with LPS treated rats. EETC (200 and $400 \mathrm{mg} / \mathrm{kg}$ ) administered group significantly $(P<0.001)$ decreased the level of TBARS when compared to LPS treated group but the effect is less significant than Aspirin treated group. EETC $400 \mathrm{mg} / \mathrm{kg}$ administered group exerted its better anti-oxidant activity by decreased the level of TBARS when compared to EETC (200 mg/kg) (Table 3).

Effect of EETC on LPS induced alterations in CAT level: LPS treated group significantly $(P<0.001)$ decreased the level of CAT when compared to control group. Aspirin treated group significantly $(P<0.001)$ increased the CAT level compare to LPS treated rats. EETC ( 200 and $400 \mathrm{mg} / \mathrm{kg}$ ) treated group significantly $(P<0.001)$ increased the CAT level when compared to LPS treated group but less increase when compared to control and Aspirin treated group. There was no significant difference on the activity between the EETC $(200 \mathrm{mg} / \mathrm{kg})$ and EETC $(400 \mathrm{mg} / \mathrm{kg})$ treated groups (Table $\mathbf{3}$ ).

Histopathological assessment of EETC in hippocampus region using crystal violet staining: There was a decrease in the neuronal cells, increased in chromatolysis and pyknotic nuclei in LPS treated rats in the region of Hippocampal brain slices when compared to control rats. Aspirin treated rats showed an increase in the regeneration of neuronal cells compared to LPS rats. EETC (200 $\mathrm{mg} / \mathrm{kg}$ ) and EETC $(400 \mathrm{mg} / \mathrm{kg})$ treated rats showed significantly decrease in cell edema, neuronal cell degeneration compared to LPS treated rats by dose dependently (Figures $4 a-4 e)$.

\section{Discussion}

The central findings of the current study reveal that EETC attenuates LPS induced sickness behavior on rats. LPS can bind with TLR4 leading to the activation of NF-KB-dependent induction of pro-inflammatory cytokines such as TNF- $\alpha$, IL- $1 \beta$, IL- 6 and COX which leads to sickness behavior. These findings replicate the results of many previous studies, which demonstrated that activation of the immune system by LPS induces a Sickness behavior which refers to a coordinated set of behavioral changes that develop during the course of raised systemic inflammation [26] and include reduction in appetite and body weight, suppression of locomotor, exploratory, and social activity, fatigue and malaise, impairment in cognitive abilities, reduced libido and sexual behavior, anhedonia and impairment in motor behavior [27-29].

In our present study LPS treated rats showed decrease in body weight when compared to control rats due to stress. The body weight was increased to rats were treated with Aspirin and EETC (200 and $400 \mathrm{mg} / \mathrm{kg}$ ) results from anti-stress activity with active food intake when compared to LPS treated group. The presence of alkaloids and diterpenoid lactone contents exert an antistress activity of EETC [30]. LPS produced a marked elevation in rectal temperature 1-3 $\mathrm{h}$ after i.p. administration. Some of the changes may found in neurotransmitter activities such as 5-HT and NE could account for this effect of LPS [31,32]. LPS produced a biphasic effect on body temperature, with an initial hypothermia, followed by a febrile phase where hyperthermia produced. The extract of $T$. cordifolia produced very good antipyretic effect in a dose-dependent manner and the observed

Table 2 Effect of EETC on LPS induced memory impairment in passive avoidance test.

\begin{tabular}{|c|c|c|}
\hline Treatment & Acquistion Trail (Day 1) & Retention Latency (Day2) \\
\hline Control & $15.50 \pm 1.08$ & $78.67 \pm 3.87$ \\
\hline LPS $(100 \mu \mathrm{g} / \mathrm{kg}, \mathrm{ip})$ & $26.67 \pm 0.66$ & $24.17 \pm 1.16 c$ \\
\hline Aspirin (200 mg/kg, po) & $16.33 \pm 0.61$ & $111.7 \pm 4.82 z$ \\
\hline EETC (200 mg/kg, po) & $19.67 \pm 1.20$ & $97.33 \pm 2.24 z$ \\
\hline EETC (400 mg/kg, po) & $18.33 \pm 1.49$ & $92.00 \pm 1.69 z$ \\
\hline
\end{tabular}

Table 3 Effect of EETC on LPS induced alterations in GSH, SOD, TBARS and CAT levels.

\begin{tabular}{|c|c|c|c|c|}
\hline Treatment & GSH (nmoles/g tissue) & SOD (units/min/mg protein) & TBARS (nmoles/mg protein) & CAT (mg protein/min) \\
\hline Control & $35.42 \pm 6.42$ & $8.12 \pm 2.08$ & $1.85 \pm 0.12$ & $3.98 \pm 1.26$ \\
\hline LPS $(100 \mu \mathrm{g} / \mathrm{kg}, \mathrm{ip})$ & $21.26 \pm 2.49 \mathrm{c}$ & $3.92 \pm 1.94 \mathrm{c}$ & $4.59 \pm 0.96 \mathrm{c}$ & $1.43 \pm 0.93 \mathrm{c}$ \\
\hline Aspirin $(200 \mathrm{mg} / \mathrm{kg}, \mathrm{po})$ & $32.18 \pm 8.16 \mathrm{z}$ & $7.43 \pm 2.96 \mathrm{z}$ & $1.98 \pm 0.23 \mathrm{z}$ & $3.21 \pm 1.34 \mathrm{z}$ \\
\hline EETC $(200 \mathrm{mg} / \mathrm{kg}, \mathrm{po})$ & $27.34 \pm 6.32 \mathrm{x}$ & $5.97 \pm 0.98 \mathrm{z}$ & $2.82 \pm 0.46 \mathrm{y}$ & $2.29 \pm 2.56 \mathrm{y}$ \\
\hline EETC $(400 \mathrm{mg} / \mathrm{kg}, \mathrm{po})$ & $29.31 \pm 8.34 \mathrm{y}$ & $6.58 \pm 1.02 \mathrm{z}$ & $2.12 \pm 0.12 \mathrm{z}$ & $2.98 \pm 1.45 \mathrm{z}$ \\
\hline
\end{tabular}




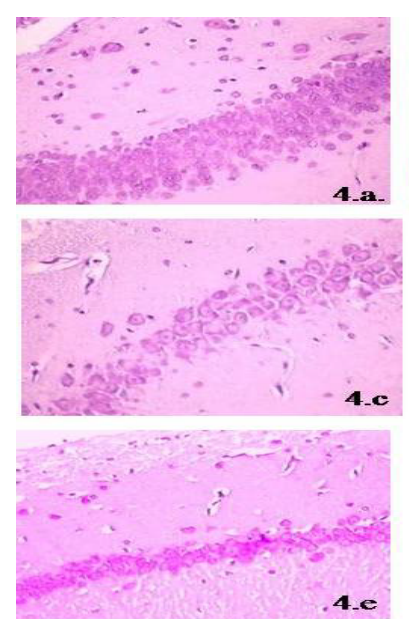

Figure 4

Histopathological assessment of EETC in hippocampus region using cresyl violet staining. $4 a$. Control rats 4b. LPS treated rats 4c. EETC $200 \mathrm{mg} /$ kg. 4d. EETC $400 \mathrm{mg} / \mathrm{kg}$. 4e. Aspirin $200 \mathrm{mg} / \mathrm{kg}$.

effect was almost similar to that in the Aspirin-treated group. The antipyretic properties of $T$. cordifolia exerted due to the presence of berberine [33], diterpenoid lactones, aliphatic compounds and steroids [34]. The previous studies were showed the presence of water-soluble fractions of $95 \%$ ethanolic extract of T. cordifolia plant to possess significant antipyretic activity [35].

Following LPS injection in rats, a change in the total locomotion as depicted from decrease activity in Actophotometer was observed [36]. Administration of ethanolic extract of $T$. cordifolia and Aspirn increases the locomotion activity in rats compared to LPS treated group. The increase in the locomotion due to the presence of glycosidal contents in the plant [37] and thereby, suppresses the depression and anxiety in rats.

LPS treated rats produced cognitive and memory impairment shows decreased in latency period in passive avoidance test. The activation of inflammatory mediators upon microglial activation affects the hippocampus function [38]. Our present investigation exhibits anti-inflammation and cognitive stabilization by increasing retention latency period upon administration of EETC (200 and $400 \mathrm{mg} / \mathrm{kg}$ ) and Aspirin (200 mg/kg). The EETC produces cognitive enhancement by the presence of glycosidal contents [37] and synthesis of acetylcholine. The increased level of choline shows memory enhancing property for learning and memory in normal and memory-deficits animals [39].

The tripeptide GSH is an important endogenous anti-oxidant which has a major role in restoring other free radical scavengers and anti-oxidants, such as vitamins $\mathrm{C}$ and $\mathrm{E}$, to their reduced state [40]. The decreased level of GSH observed upon administration of LPS due to oxidative damage when compared to control group. The EETC $(200 \mathrm{mg} / \mathrm{kg}$ and $400 \mathrm{mg} / \mathrm{kg}$ ) treated rats restored the GSH level compared to LPS treated rats due to presence of highest phenolic contents [41] and extracts showing highest free radical scavenging activity. However, Aspirin significantly elevated the activities of antioxidative enzymes compared to LPS-treated animal.

Living organisms contain SOD, which removes superoxide, and are thus protected from injury caused by ROS [42]. A significant decrease in the enzyme activity of SOD was observed as a result of increased superoxide formation upon LPS administration at day 14 [36] due to oxidative stress. EETC produced positive modulatory effect on cellular anti-oxidant system by increasing the anti-oxidant level of SOD. The antioxidative activity of EETC $(400 \mathrm{mg} / \mathrm{kg})$ was potent than that of EETC $(200 \mathrm{mg} / \mathrm{kg})$. The increased level of SOD was observed on Aspirin treated rats when compared to LPS treated rats.

TBARS level elevated in the LPS administered rat due to oxidative stress of cells. The anti-oxidant property of Aspirin was enhanced by decreasing the formation of TBARS. The formation of TBARS in the brain was inhibited in a concentration dependent manner in presence of EETC, as the EETC $(400 \mathrm{mg} / \mathrm{kg})$ shows potent suppression of TBARS than EETC $(200 \mathrm{mg} / \mathrm{kg})$ in rats. This study supported from previous reports that, the $(1,4)$-alpha-d-glucan (alpha-d-glucan), derived from $T$. cordifolia have been shown to activate human lymphocytes with downstream synthesis of the pro- and anti-inflammatory cytokines, in vitro. Its ability to destroy cellular metabolic waste products may be responsible for the anti-oxidant effect and strengthens the tissues [43].

Catalase mediates its function by the removal of $\mathrm{H}_{2} \mathrm{O}_{2}$ generated by auto-oxidation of lipids and the oxidation of organic substances [36]. The study revealed that LPS treatment suppressed the CAT activities when compared to control group. The administration of EETC following LPS in rats reported to show scavenge activity due to the presence of antioxidants and had protective effect by increasing the CAT level. The anti-oxidant activity of Aspirin $(200 \mathrm{mg} / \mathrm{kg}$ ) treated rats showed by increase in the CAT level. The anti-oxidant property was higher in the dose of $400 \mathrm{mg} /$ $\mathrm{kg}$ of EETC than in $200 \mathrm{mg} / \mathrm{kg}$ of EETC administered rats. The result supported from previous studies that, $T$. cordifolia contains Flavonoids, glycosides, saponins and some amount of phytosterols. These active constituents alone or in combination may be responsible for the observed antioxidant activity [44].

The LPS administration on rats caused neuronal injury induced cell damage on Hippocampal slices was observed clearly when compared with control because of microglial activation results in immunostimulation $[45,46]$. After treatment with the EETC showed increase in the regeneration of neuronal cells with composite nature and same process obtained from Aspirin treated group. This clearly showed that EETC protects the cells from get damage by built up of neuronal cell structure and reduces the cell edema. EETC $400 \mathrm{mg} / \mathrm{kg}$ dose expressed better protection when compared to $200 \mathrm{mg} / \mathrm{kg}$ of EETC and the results 
obtained concludes the neuroprotective effect of EETC on brain from LPS inflammation.

\section{Conclusion}

The ethanolic extract of Tinospora cordifolia may elicit neuroprotective activity due to the presence of phytochemical

\section{References}

1 Kent S, Bluthe RM, Kelley KW, Dantzer R (1992) Sickness behavior as a new target for drug development. Trends Pharmacol Sci 13: 24-28.

2 Yirmiya R (1996) Endotoxin produces a depressive like episode in rats. Brain Res 711: 163-168.

3 Raetz C, Whitfield C (2002) Lipopolysaccharide endotoxins. Annu Rev Biochem 71: 635-700.

4 Tzeng YL, Datta A, Kolli VK, Carlson RW, Stephens DS, et al. (2002) Endotoxin of Neisseria meningitidis composed only of intact lipid A: inactivation of the meningococcal 3-deoxy-D-manno-octulosonic acid transferase. J Bacteriol 184: 2379-2388.

5 Coats SR (2005) MD-2 mediates the ability of tetra-acylated and penta-acylated lipopolysaccharides to antagonize Escherichia col lipopolysaccharide at the TLR4 signaling complex. J Immunol 7: 4490-4498.

6 Pugin J, Schurer-Maly CC, Leturcq D, Moriarty A, Ulevitch RJ, et al. (1993) Lipopolysaccharide activation of human endothelial and epithelial cells is mediated by lipopolysaccharide-binding protein and soluble CD14. Proc Natl Acad Sci USA 90: 2744-2748.

7 Chow JC, Young DW, Golenbock DT, Christ WJ, Gusovsky F, et al. (1999) Toll-like receptor-4 mediates lipopolysaccharide-induced signal transduction. J Biol Chem 274: 10689-10692.

8 Akira S, Takeda K (2004) Toll-like receptor signalling. Nat Rev Immunol 4: 499-511.

9 Morris T, Stables M, Hobbs A, Patricia de Souza, Colville-Nash P, et al. (2009) Effects of low-dose aspirin on acute inflammatory responses in humans. J Immunol 183: 2089-2096.

10 Hinz B, Cheremina O, Brune K (2008) Acetaminophen (paracetamol) is a selective cyclooxygenase-2 inhibitor in man. FASEB J 2: 383-390.

11 Rostom A, Dube C, Wells G, Tugwell P, Welch V, et al. (2002) Prevention of NSAID-induced gastroduodenal ulcers. Cochrane Database Syst Rev 4: CD002296.

12 https://www.drugs.com/sfx/naloxone-side-effects.html

13 Anonymous (1976) Wealth of India: Raw materials, Vol X. New Delhi: CSIR, India.

14 Nadkarni KM, Nadkarni AK (1976) Indian Materia Medica. Mumbai: M/S Popular Prakasan Pvt. Ltd, India.

15 Kirtikar KR, Basu BD (1975) Indian medicinal plants. Dehra Dun: M/S Bishen Singh, Mahendra Pal Singh, India..

16 Chopra RN, Nayar SL, Chopra IC (1956) Glossary of indian medicinal plants. New Delhi: CSIR. India.

17 Chopra RN, Chopra LC, Handa KD, Kapur LD (1982) Indigenous drugs of India. Kolkata: M/S Dhar VN \& Sons, India.

18 Zhao TF, Wang X, Rimando AM, Che C (1991) Folkloric medicinal plants: Tinospora sagittata var. cravaniana and Mahonia bealei. Planta Med 57: 505. constituents such as alkaloids, glycosides, diterpenoid lactones, berberine, flavonoids, saponins.

\section{Acknowledgement}

We are grateful to thank the Principal, KK College of Pharmacy., Chennai, Tamil Nadu, India, for providing research facilities.

19 Reddy DS, Kulkarni SK (1998) Possible role of nitric oxide in the nootropic and antiamnestic effects of neurosteroids on aging- and dizocilpine-induced learning impairment. Brain Res 2: 215-229.

20 Wang YJ, Zheng YL, Lu J, Chen GQ, Wang XH, et al. (2010) Purple sweet potato color suppresses lipopolysaccharide-induced acute inflammatory response in mouse brain. Neurochem Int 56:424-30.

21 Sapakal VP, Shikalagar TS, Ghadge (2008) In vitro screening of antioxidant profile. A review. Herb Med Toxicol 2: 1-8.

22 Misra HP, Fridovich I (1976) The oxidation of phenylhydrazine: Superoxide and mechanism. Biochemistry 15: 681-687.

23 Ohkawa H, Ohishi N, Yagi K (1979) Assay for lipid peroxides in animal by thiobarbituric acid reaction. Analytical Biochem 2: 351-358.

24 Aebi H (1984) Catalase in vitro. Methods in Enzymology. New York: USA. Academic press. pp. 121-126.

25 Takanaga A, Hayakawa T, Tanaka K, Kawabata K, Maeda S, et al. (2003) Immunohistochemical characterization of cardiac vagal preganglionic neurons in the rat. Auton Neurosci 106: 132-137.

26 Holmes C, Cunningham C, Zotova E, Culliford D, Perry VH, et al. (2011) Proinflammatory cytokines, sickness behavior, and Alzheimer disease. Neurology 3: 212-218.

27 Anisman H, Merali Z (1999) Anhedonic and anxiogenic effects of cytokine exposure. In: Dantzer R, Wollman EE, Yirmiya R (eds). Cytokines, stress, and depression. New York, Kluwer Academic/ Plenum Publishers. pp. 199-233.

28 Dantzer R, Wollman EE, Vitkovic L, Yirmiya R (1999) Cytokines and depression: Fortuitous or causative association? Mol Psychiat 4: 328-332

29 Maier SF, Watkins LR (1998) Cytokines for psychologists: Implications of bidirectional immune-to-brain communication for understanding behavior, mood, and cognition. Psych Rev 105: 83-107.

30 Singh SS, Pandey SC, Srivastava S, Gupta VS, Patro B, et al. (2003) Chemistry and medicinal properties of Tinospora Cordifolia (Guduchi). Indian J Pharmacol 35: 83-91.

31 Ford DM, Klugman KP (1980) Contrasting roles of 5-HT and nordrenaline in fever in rats. J Physiol 249: 51-57.

32 Matsuzek M, Ishikawa Y (1981) Effects of 5,7-dihydroxytryptamine and 6-hydroxydopamine on fever response in conscious rats. Pol J Pharmacol Pharm 33: 305-312.

33 Rao EV (1999) Chemistry and Pharmacological studies on Tinospora species- A review. Indian Drugs 36: 78-86.

34 Meshram A, Sameer S. Bhagyawant, Gautam S, Shrivastava N (2013) Potential role of Tinospora cordifolia In Pharmaceuticals. WJPPS 6 : 4615-4625.

35 Vedavathy S, Rao KN (1991) Short communication: Antipyretic activity of six indigenous medicinal plants of Tirumala Hills, Andhra Pradesh, India. J Ethnopharmacology 33: 193-196.

36 Sharma N, Nehru B (2015) Characterization of the lipopolysaccharide 
induced model of Parkinson's disease: Role of oxidative stress and neuroinflammation. Neurochemistry International 87: 92-105.

37 Mittal J, Sharma MM, Batra A (2014) Tinospora cordifolia: A multipurpose medicinal plant- A review. J Med Plants Stud 2: 32-47.

38 Gong QH, Wang Q, Pan L, Liu XH, Xin H, et al. (2011) S-Propargylcysteine, a novel hydrogen sulfide-modulated agent, attenuates lipopolysaccharide-induced spatial learning and memory impairment: Involvement of TNF signaling and NF-KB pathways in rats. Brain Behav Immun 25: 110-119.

39 Lannert H, Hoyer S (1998) Intracerebroventricular administration of streptozotocin causes long-term diminutions in learning and memory abilities and in cerebral energy metabolism in adult rats. Behavioral Neurosci 5: 1199-1208.

40 Kaur G, Tirkey N, Bharrhan S, Chanana V, Rishi P, et al. (2006) Inhibition of oxidative stress and cytokine activity by curcumin in amelioration of endotoxin-induced experimental hepatoxicity in rodents. British Society for Immunology, Clinical and Experimental Immunology 145:313-332.
41 Upadhyay N, Ganie SA, Agnihotri RK, Sharma R (2014) Free radical scavenging activity of Tinospora cordifolia (Wild.) Miers. J Pharmacogn Phytochem 2: 63-69.

42 Sharma G, Nath R, Gill KD (1991) Effect of ethanol on cadmiuminduced lipid peroxidation and antioxidant enzymes in rat liver. Biochemical Pharmaco 42: S9-S16.

43 Saha s, Ghosh S (2012) Tinospora cordifolia: One plant, many roles. Anc Sci Life 31: 152.

44 Onkar P, Bangar J, Karodi R (2012) Evaluation of antioxidant activity of traditional formulation Giloy satva and hydroalcoholic extract of the Curculigo orchioides gaertn. J Appl Pharmaceutical Sci 6: 209-213.

45 Hauss-Wegrzyniak, Dobranski P, Stoehr JD, Wenk GL (1998) Chronic neuroinflammation in rats reproduces components of the neurobiology of Alzheimer's disease. Brain Res 780: 294-303.

46 Hauss-Wegrzyniak, Lukovic L, Bigaud M, Stoeckel ME (1998) Brain inflammatory response induced by intracerebroventricular infusion of lipopolysaccharide: An immunohistochemical study. Brain Res 794: 211-224. 